\title{
Examining Racial and Ethnic Variations in Reasons for Leaving a Youth Gang
}

Dena C. Carson

Indiana University Purdue University Indianapolis

Dena C. Carson

School of Public and Environmental Affairs

IUPUI

801 W. Michigan Street

Indianapolis, IN 46201

317-274-8707

carsond@iupui.edu

Acknowledgements:

This research was made possible, in part, by the support and participation of seven school districts, including the School District of Philadelphia. This project was supported by Award No. 2006-JV-FX-0011 and Award No. 2011-JP-FX-0101 from the National Institute of Justice, Office of Justice Programs, U.S. Department of Justice. The opinions, findings, and conclusions or recommendations expressed in this manuscript are those of the authors and do not necessarily reflect the views of the Department of Justice or of the seven participating school districts. The author would like to thank Finn-Aage Esbensen for his comments on an earlier draft of this paper.

This is the author's manuscript of the article published in final edited form as:

Carson, D. C. (2018). Examining Racial and Ethnic Variations in Reasons for Leaving a Youth Gang. Journal of Developmental and Life-Course Criminology, 4(4), 449-472. https://doi.org/10.1007/s40865-018-0091-z 
Examining Racial and Ethnic Variations in Reasons for Leaving a Youth Gang

\begin{abstract}
Purpose One underrepresented area of research within the developmental and life course framework is how criminal careers vary across racial and ethnic lines. Similarly, little is known about how the processes surrounding leaving a youth gang differ based the experiences of racial and ethnic minorities. This manuscript will help fill this gap in both bodies of literature by examining differences in push and pull motivations for gang desistance across black, Hispanic, and white youth who reside in seven different cities across the U.S.

Methods The mixed-method analysis relies on grounded theory techniques to identify themes in the qualitative interviews as well as provides a quantitative comparison of gang desistance motivations.

Results Black youth were least likely to report pulls associated with prosocial attachments and were also least likely to report being disillusioned with intragang relationships. Hispanic youth most commonly reported pulls associated with parental encouragement and experiencing official sanctions and pushes centered on direct and vicarious violent experiences. White youth most commonly reported pulls associated with having a significant other and pushes including feelings of disillusionment with intragang relationships.

Conclusion While there is evidence that street socialization and social isolation uniquely impact the gang desistance decisions of black gang youth, these differences might not be enough to justify race-specific intervention programs.
\end{abstract}

Keywords: gang, gang desistance, race/ethnicity 


\section{Introduction}

The study of gang desistance or how youth disengage from gang life ${ }^{1}$ has benefited immensely from life course and developmental perspectives on desistance from crime. This is expected given that trajectories of gang membership mirror those of general criminal offending as both consist of a beginning (e.g., joining the gang), middle (e.g., periods of active membership), and end (e.g., leaving the gang) (Thornberry et al. 2003). Similar to desistance from crime, leaving the gang is a process that is believed to involve both turning points and identity transformation that work together to help individuals break away from gang life. Turning points are external to the individual and consist of life events that are significant enough to alter one's criminal trajectory (Elder 1985; Sampson and Laub 1993). While access to turning points can be dependent upon age, they are often triggered by prosocial institutions such as marriage, school, employment, and parenthood (Laub and Sampson 2001; Sampson and Laub 1993). The processes surrounding human agency and identity transformation are also important to the desistance process (Giordano et al. 2007; Maruna 2001). It is these cognitive transformations that allow individuals to take advantage of or select hooks for change (Giordano et al. 2002; Giordano et al. 2007).

Certainly, understanding of the processes surrounding leaving a gang has benefited from this body of work especially as it relates to the reasons youth give for leaving a gang, which are often consistent with both identity transformations and turning points frameworks. Similar to motivations for joining a gang, these motivations are typically categorized into pull or push factors. Pull factors, similar to turning points, present new opportunities to gang members that make life outside the gang more attractive or less of a priority (e.g., mobility, prosocial activities,

${ }^{1}$ Please note that I use gang desistance and gang disengagement interchangeably throughout the manuscript. 
etc.) (Bjorgo 2002; Pyrooz and Decker 2011; Roman et al. 2017). Push factors are more closely associated with identity transformations and are believed to be internal to the gang member (Decker et al. 2014a; Pyrooz and Decker 2011). These identity transformations can be brought on by negative experiences associated with gang membership (e.g., victimization, arrest, etc.), which push the individual toward an identity that is more prosocial (Roman et al. 2017). Previous research on gang desistance has improved our understanding of the prevalence of push and pull factors, but we know little about how these factors may vary across demographic variables. We are beginning to understand variations in the gang desistance processes across gender (see Miller 2001, O'Neal et al. 2016, and Peterson 2012), but little is known about why belonging to a racial/ethnic minority group may hinder or facilitate the gang desistance process.

The lack of research on how the experience of leaving a gang may vary across one's race or ethnicity is not surprising given that it is largely absent from the broader body of life course and developmental research on offending (Piquero 2015). Piquero (2015) argues that lack of data sources have played a role in the underrepresentation of race/ethnic perspectives on crime over the life course. This is certainly true for research on gang disengagement as the majority of prior work has been unable to examine racial/ethnic variations in breaking away from gang life due to data consisting of a single race/ethnicity (e.g., African American or Hispanic gang members). These works have been extremely valuable in understanding the unique experiences of these gang members, but are not well-suited for making comparisons across racial and ethnic groups. Such comparisons can only be made when equivalent data are gathered on gang members of different racial and ethnic backgrounds. Moreover, gang desistance research that encompasses youth of multiple racial and ethnic backgrounds has yet to include race-specific analysis on the 
processes involved in leaving a gang (Decker and Pyrooz 2011; Decker et al 2014a; Miller 2001 - see Carson et al. 2013 for an exception).

By understanding racial and ethnic variations in how youth discuss their motivations for leaving the gang, this work will help to build the body of research on racial and ethnic variations in criminal careers over the life course. Additionally, this manuscript will complement recent work that explores factors that facilitate or hinder the gang desistance process such as school transitions and parenthood (Carson et al. 2017; Pyrooz et al. 2017). Previous research examining trajectories of gang membership has found that minority gang youth tend to stay in a gang for longer periods of time than their white counterparts (Pyrooz 2014; Pyrooz et al. 2013), but little is known about why belonging to a racial/ethnic minority group may slow the gang desistance process. While this work is unable to examine the entire gang desistance process, understanding racial and ethnic variation in the decision to leave a gang contributes to knowledge on an important portion of this process. Moreover, a more nuanced picture of how motivations for leaving a gang vary by race/ethnicity is warranted given racial and ethnic disparities in risk factors, gang membership, offending, and criminal justice involvement (Elliott 1994; Esbensen et al. 2010; Hawkins et al. 1998; Piquero et al. 2005). In terms of gang membership, minority youth are overrepresented in gangs with both official records and self-report studies indicating that 21 to 38 percent of gang members are black, 19 to 54 percent are Hispanic/Latino, and 10 to 24 percent are white (Esbensen and Carson 2012; Esbensen et al. 2010; Hill et al. 1999; National Gang Center, 2011; Pyrooz 2014; Thornberry et al. 2003). Drawing on literature that attempts to explain these disparities may help us to understand racial and ethnic variations in reasons for leaving a gang and, thus, why minority youth spend more time as active gang members. 
As discussed by Roman and colleagues (2017), the reasons youth give for breaking away from gang life might be particularly helpful in developing interventions and determining appropriate programs to reduce gang membership and gang crime. They argue that many current programs are already using both push and pull factors to reduce both gang involvement and gang behavior. This work will improve understanding on what might work best for gang involved youth of varying racial and ethnic backgrounds. For example, if black gang members report more pull versus push factors, then programs that improve prosocial bonding and new opportunities might be better suited for this population (Roman et al. 2017). That said, evidence of similar motivations for leaving a gang across racial and ethnic lines may warrant a "one size fits all" approach to gang intervention (Esbensen et al. 2010; Freng and Taylor 2013).

By exploring racial and ethnic variations in reasons for leaving the gang, I will be contributing to the broader body of research on life course and developmental theories as well as research that focuses broadly on the gang exit process. While gang disengagement might be seen as a small portion of one's criminal career and desisting from gang life does not equal desistance from crime, it remains an important area of concern for researchers given the amount of crime committed by gang members and that membership elevates offending levels (Esbensen and Huizinga 1993; Gordon et al. 2004; Melde and Esbensen 2013; Thornberry et al. 1993). Additionally, this manuscript will benefit from the use of a mixed-methods approach to compare and contrast motivations for gang desistance in a sample of black, Hispanic, and white youth across seven different cities. Using a mixed-methods approach will improve upon previous purely quantitative or qualitative studies by being able to triangulate and improve validity in regards to the differences in reasons for leaving a gang (Maruna 2010). Additionally, the diverse 
nature of this sample will help to account for some of the limitations of prior work and improve our knowledge on racial/ethnic similarities and differences in reasons for leaving a gang.

\section{Racial/Ethnic Differences in the Life Course}

Though life course and developmental work has been limited in its ability to explain or address racial and ethnic differences in criminal careers, one notable exception to this is Moffitt's (1994) explanation of how race and ethnicity, particularly in the American context, may increase the prevalence of both life course persistent and adolescent limited offenders. In her discussion she points to a number of risk factors that have been cited in the large body of work which tries to understand racial and ethnic differences in offending. This work argues that contextual factors such as institutionalized racism, segregation, and urban inequality (Logan and Messner 1987; Massey and Denton 1993; Moffitt 1994; Peterson et al. 2006; Sampson and Wilson 1995; Vigil 1988) and accompanying high levels of poverty, unemployment, and concentrated disadvantage (McNulty and Bellair 2003; Morenoff and Sampson 1997; Piquero et al. 2004; Sampson 1987; Sampson and Groves 1989) interact with other risk factor domains (e.g., individual, family, peer, and school) to create differential patterns of offending among racial and ethnic minorities. From Moffitt's perspective, the impact of these contextual factors begins at a young age with poor nutrition and exposure to toxins beginning in infancy, which places youth at risk for nervous systems problems that Moffitt states have been "shown to interfere with prosocial child development (Moffitt 1994:39).”

The racial segregation and concentrated disadvantage associated with minority neighborhoods is also believed to lead to blocked opportunities as well as social isolation and street socialization (Sampson and Wilson 1995). These factors can be particularly harmful from a life course perspective because they block maturational reform (Elliott 1994) and result in more 
time spent in the "maturity gap" (Moffitt 1994). In other words, minorities are blocked from adult opportunities and roles such as those provided by employment. Haynie and colleagues (2008), finding support for Moffitt's work, report that blocked economic and employment prospects mediated the impact of race on crime. From a social isolation perspective, racial segregation and neighborhood disadvantage block minorities from mainstream society (Wilson 1987), which in combination with the lack of social control and collective efficacy (Bursik and Grasmick 1993; Sampson et al. 1997) present in disadvantaged neighborhoods can lead to street socialization (Anderson 1999; Wolfgang and Ferracuti 1969). According to Moffitt (1994) this isolation will result in increased exposure to life course persistent offenders among minority youth.

Poverty and community disadvantage can produce a great deal of strain on the family unit, which has led to the breakdown of social bonds to the family (Hawkins et al. 1998; Malec 2006; McNulty and Bellair 2003; Moffitt 1994). Minority youth are more likely to be raised in single parent households (Wilson 1996), which could result in a tangible reduction in supervision, increased time spent in unstructured activities with peers (Piquero et al. 2005) as well as underlying emotional disturbances caused by not having parental support or affection (Adler et al. 1984; Vigil 1988). It is important to highlight, however, that family is held in particularly high regard within the Hispanic culture. Hispanic youth tend to have stronger emotional bonds to their family and are more invested in their family (Bourgois 1996; Krohn et al. 2011a) — which can make them less susceptible to peer pressure (Horowitz 1983; Martinez 2002). That said, this connection is thought to be eliminated as Hispanic youth become more acculturated in American society and dissonance between the traditional culture and American culture increases (Krohn et al. 2011a). A part from difficulties in their own families, research has 
also found race/ethnic differences in the likelihood of marriage as well as quality of marriage (Bulanda and Brown 2007; Elliott 1994; Hawkins et al. 1998; Haynie et al. 2008; South 1993; Wilson 1987).

Schools play an important role in the socialization of youth and minorities disproportionately attend schools with poor climate (Payne and Welch 2010; Welsh et al. 1999) and experience differential punishments at school (Kupchik 2010; Payne and Welch 2010; Skiba et al. 2011; Skiba et al. 2002). It is unsurprising then that minority youth are more likely to experience school failure and have higher dropout rates. Relatedly, Moffitt (1994) notes that disadvantaged schools are unable to address learning disabilities that will further impact youth in their life course. Low levels of connection to school may be exacerbated among Hispanic youth (Miller et al. 2011; Vigil 1988, 1999). The complicated relationship between Hispanic youth and school is thought to be attributed to low levels of education among Hispanic parents, which results in lower educational expectations for their children and a lack of understanding about the importance of education (Del Pinal and Singer 1997; Krohn et al. 2011a). Additionally, cultural barriers, especially as they relate to language, are likely to make the school system more difficult to navigate for Hispanic youth and their parents (Bourgois 1996; Krohn et al. 2011a; Miller et al. 2011; Padilla 1992; Vigil 1988).

Notably, Moffitt (1994:39) argues that these factors all coalesce to produce a "snowball of cumulative continuity" that endures across the life course of minority youth. In other words, it is not simply one risk factor that leads to more lengthy offending patterns. Minority youth are more likely to reside in areas that are subject to segregation and disadvantage, which, in turn influences their connections to other social institutions including the family and school. Therefore, despite the relatively young age in which youth leave a gang, minority gang members 
are already being impacted by the broader structural disadvantages that shape access to the prosocial institutions and opportunities that shape not only their life course, but also their gang desistance processes.

\section{Pushes and Pulls of Gang Disengagement}

Just as the above factors set the stage for persistent offending as well as gang membership, they can also alter the process of disengaging from gang life, even at a young age, by impacting identity transformation and access to turning points. Identity transformation is believed to play a key role in the gang disengagement process and "hooks for change" may be disregarded without associated identity transformation (Bushway and Paternoster 2013; Giordano et al. 2007). Gang desistance research identifies push factors as those that are closely in line with the role that human agency and changes in identity play in the decision to leave a gang. Push factors are those that make life in the gang seem undesirable and, thus, encourage gang youth to rethink their gang member identity.

Feelings of disillusionment with gang life, maturation, violence fatigue are often considered pushes away from gang life. Feeling disillusioned with gang life is one of the most common motivations for gang desistance (Carson et al. 2013; Decker and Lauritsen 2002; Decker et al. 2014a; Padilla 1992; Pyrooz and Decker 2011). This is represented by vague statements such as "I just felt like leaving" or "I got tired of the gang lifestyle" (Carson et al. 2013; Pyrooz and Decker 2011) as well as those highlighting dissatisfaction with intragang relationships (e.g., drama, lack of gang support) (Bjorgo 2002; Decker et al. 2014a; Hagedorn 1994; Padilla 1992; Vigil 1988). Related are feelings of maturation in which gang members report that they are simply growing up and out of the gang lifestyle (Decker and Pyrooz 2011; Decker et al. 2014a; Decker and Van Winkle 1996; Hagedorn 1994; Thrasher 1927/1963; Vigil 
1988). Adverse life experiences or circumstances such as direct and vicarious violence as well as incarceration and police contact can also be considered push motivations because experiencing them, as a result of belonging to a gang, could facilitate the underlying processes associated with identity transformation (Roman et al. 2017). Therefore, experiences with direct or indirect/vicarious violence are thought of as push factors away from gang life.

As part of the isolation associated with living in a disadvantaged neighborhood, minority youth are socialized into a street identity (i.e., Anderson 1999) and the acceptance of violent attitudes among gang youth is well supported in the literature (Alleyne et al. 2014; Alleyne and Wood 2010; Esbensen et al. 2010; Matsuda et al. 2013; Melde and Esbensen 2011, 2014). Greater acceptance of violent norms could hinder the gang desistance process by making identity transformations more difficult and, therefore, push motivations less salient for minority youth. For example, it may be difficult to envision oneself in a new role or explore different nongang identities (see Ebaugh 1988 and Decker et al. 2014a) when isolated from prosocial role models and norms.

Turning points are also an intricate part of the gang exit process, but access to these turning points is impacted, not only by the age of the gang member, but also by the structural disadvantages experienced by minority youth, which can reduce social capital and opportunities needed to access prosocial institutions that can aid in the gang desistance process (Bracken et al. 2009; Hagedorn 1988; Pyrooz et al. 2013). While generally associated with prosocial events, prior research has identified negative turning points such as victimization and incarceration (Jacques and Wright 2008; Sampson and Laub 2016; Soyer 2014), which can, and sometimes do, accompany identity transformations. In the gang desistance literature, pull factors are commonly associated with turning points because they present new, often prosocial opportunities, outside of 
the gang realm (e.g., increased family responsibilities, employment, mobility, etc.). These turning points, when combined with cognitive shifts in identity, can act as hooks for change because they present prosocial opportunities or roles that improve bonds to conventional society.

Experiencing police contact or official sanctions (e.g., jail, juvenile detention) has been cited in prior work as a motivation for leaving the gang (Carson et al. 2013; Decker and Pyrooz 2011; Decker et al. 2014a; Hagedorn 1994; Moore 1991; Vigil 1988). These experiences can be seen as turning points, but also as the impetus for identity transformations. Due both to the neighborhoods they reside in and their status as minorities, black, and to a lesser extent Hispanic youth, have more frequent contact with the police as well as the justice system. These experiences, as well as the street socialization common among minority youth, results in less favorable perceptions of the police and undermines the ability of police to interact positively with minority youth (Brunson 2007; Brunson and Weitzer 2009; Peck 2015; Taylor et al. 2001; Weitzer and Tuch 1999). Instead, youth only experience negative interactions with the police. This may make minority youth less likely to report that police contact and official sanctions played a role in their motivation to leave a gang.

Access to prosocial opportunities is important in the gang disengagement process. Positive experiences with informal social institutions, such as school, have been associated with motivational pulls away from gang life. For example, experiencing difficulties in an academic environment (e.g., punishments, poor grades, etc.) and becoming involved in school-based prosocial activities can motivate gang desistance (Carson et al. 2013; Vigil 1988). However, if minority youth have experienced problems in their school then they may be less likely to report that these factors benefited them when exiting the gang (Decker et al. 2014a; Moore 1991; Vigil 1988). Increased family responsibilities, such as parenthood, can lead to gang desistance, most 
commonly among girls (Miller 2001; Moloney et al. 2011; Pyrooz et al. 2017). That said, turning points like parenthood may not be common among those joining and leaving the gang at a young age. Additionally, being pressured to leave a gang by your parents or believing you are causing your parents undue stress has been viewed as a pull away from gang life (Carson et al. 2013; Decker et al. 2014a; Vigil 1988). However, given the weakened bonds associated with minority youth in disadvantaged areas, they may be less likely to report that increased family responsibilities as a motivation for gang desistance.

In addition to the differential impact on experiences with school and family, the structural disadvantages associated with racial and ethnic minorities may impact access to other turning points or pulls toward gang desistance. Moving to a new school, neighborhood, or city is a common motivation for leaving the gang (Carson et al. 2017; Carson et al. 2013; Decker and Lauritsen 2002). Access to these opportunities, however, may be structurally determined and not accessible to economically disadvantaged minority groups. That said, upward mobility may be difficult for minority families, but lateral moves are more common and mobility is high among minority youth (Haynie and South 2005; Logan and Messner 1987; South and Haynie 2004; South et al. 2007). Additionally, prosocial attachments in the form of romantic relationships (Decker and Pyrooz 2011; Moore 1991) and peer relationships (Carson et al. 2013) are discussed as motivations for desistance, but the nature of these experiences is also structurally determined and may vary by race/ethnicity.

Importantly, the role that push and pull factors play in the gang desistance process might be impacted by the age of the gang desisters or where they are in their life course. Because gang desisters tend to be young, with membership peaking at age 14 or 15 (Craig et al. 2002; Esbensen and Huizinga 1993; Huff 1998; Pyrooz 2014), a number of the traditional turning 
points (e.g., parenthood, marriage, or military service) are inaccessible to these youth.

Additionally, certain push factors might be more or less common at younger ages. Feelings of disillusionment, for example, may be particularly common among youth as they move through adolescence while those associated with maturation may be less salient. When comparing across different samples of gang desisters, Roman and colleagues (2017) found some age variation in motivations for leaving a gang. The authors attributed the differences to a lack of life experiences among younger individuals.

\section{The Current Study}

Ethnographic work on gang desistance typically finds that black and Hispanic gang members report motivations associated with violence and maturation (Decker and Lauritsen 2002; Horowitz 1983; Vigil 1988). These works, however, are limited by their reliance upon one race or ethnicity, which hinders their ability to make comparisons across race/ethnicity. The sparse literature that has examined variations in gang desistance motivations across, not within, racial and ethnic lines is able to identify small differences in both pull and push motivations. Pull motivations associated with having an adult (e.g., police, parent, other) intervene are most commonly reported by Hispanic youth, followed by black and white youth (Carson et al. 2013). Reporting motivations associated with life transitions is more common among white youth especially with regard to employment (Hagedorn 1994) and, to a lesser extent, school/residential mobility and meeting prosocial peers (Carson et al. 2013). Motivations associated with push factors such as disillusionment and violence are more common among minority youth who left the gang compared with their white counterparts (Carson et al. 2013).

While these prior works are able to make comparisons across race/ethnicity, they rely on one site (Hagedorn 1994) or one methodology (Carson et al. 2013; Hagedorn 1994). The reliance 
on a single methodological approach may provide a biased assessment of motivations for gang desistance in that research has reported differences in motivations for leaving the gang based upon method (i.e., prevalence of violence fatigue versus disillusionment). In the current study, I improve upon this research by making use of qualitative and quantitative data from a sample of black, Hispanic, and white gang youth who left the gang. Additionally, this study was conducted in seven cities across the United States. In keeping with grounded theory, I will first examine themes present in the qualitative data and then, when possible, examine the extent to which these patterns exist in the quantitative data.

Through the use of the quantitative data I will be able to 1) triangulate and validate findings from the qualitative portion and 2) extend and elaborate on previous work by Carson and colleagues (2013). While this work found that the motivations, methods, and consequences of gang desistance were substantively similar regardless of race/ethnicity, it was limited by its reliance on a pooled cross-sectional sample of gang desisters. Due to the pooled nature of the data, gang desistance categories were not mutually exclusive and, thus, the authors could not examine the presence of statistical differences across racial and ethnic lines. Additionally, this work examined categories of gang desistance motivations (e.g., disillusionment, violence, adult interventions, and life transitions), which could fail to capture variation in the specific motivations across racial and ethnic lines (e.g., direct versus vicarious violence). I will extend this work by relying on a mutually exclusive sample of gang desisters as well as the disaggregated reasons youth give for leaving a gang. Overall, the reliance on mixed-methods will boost the reliability and validity of the current study (see Maruna 2010) and the large number of youth in both data sets will allow me to make use of significance testing to compare motivations across black, Hispanic, and white youth. Using these data, I will examine the following research 
questions: 1) Are minority gang desisters more or less likely to report gang disengagement motivations associated with push/pull factors and 2) Do specific pull/push motivations for gang desistance vary by race and ethnicity?

\section{Methods}

The current study relies on two connected sources of data to examine racial and ethnic differences in pull and push factors associated with leaving a gang. The quantitative sample consists of self-report surveys collected as part of the National Evaluation of the Gang Resistance Education and Training (G.R.E.A.T.) program. ${ }^{2}$ The panel design included six waves of data collected from 2006 to 2011 from youth in seven different cities in the United States: Albuquerque, New Mexico; Chicago, Illinois; Greeley, Colorado; Nashville, Tennessee; Philadelphia, Pennsylvania; Portland, Oregon; and a Dallas-Fort Worth, Texas suburb. Cities were chosen for inclusion in the evaluation based on diversity of demographic characteristics and geographic location, evidence of gang activity, and the presence of an established G.R.E.A.T. program. A total of 31 schools across these cities participated in the evaluation and 4,905 students in 195 classrooms were sampled. While all students in these classrooms were eligible to participate, the active parental consent process resulted in 4,372 consent forms returned (89\%) and 3,820 youth receiving permission to participate in the study (78\%). The evaluation team made great efforts to maintain high retention rates, which resulted in a 73 percent completion rate at wave 6.

The quantitative survey included two questions measuring gang involvement: "Have you ever been in a gang?" and "Are you currently in a gang?"3 Following work by Carson and

\footnotetext{
${ }^{2}$ For more information on the evaluation and methods please see Esbensen et al., 2013.

${ }^{3}$ Prior research has supported the use of self-nomination to measure both current and former gang status (Decker et al. 2014b; Esbensen et al. 2001; Thornberry et al. 2003).
} 
colleagues (2013), youth were classified as desisted from a gang in a given wave if they reported an affirmative response to ever gang membership and a negative response to current gang membership. In order to reduce retrospective biases, the analysis sample excluded wave 1 and 2 which did not include questions on motivations for leaving the gang and relied upon the youth's most recent report of gang desistance. ${ }^{4}$ These restrictions resulted in a sample of 425 youth who desisted from gang membership during the study period. Race/ethnicity was measured by asking youth to identify the races/ethnicities that applied to them. For ease of interpretation the sample was limited to black, Hispanic, and white youth, which resulted in a final sample size of 377. Gang desisters were mostly male, Hispanic, and reported leaving the gang around the age of 14 (see Table 1). Starting at wave 3 youth were provided a list of multiple push and pull motivations for leaving a gang and were asked to circle all that apply to them. Push motivations included: "I just felt like it"; "It wasn't what I thought it was going to be"; "I was hurt"; "A friend was hurt or killed"; and "A family member was hurt or killed." Pull motivations included: "An adult encouraged me to get out"; "My parents made me leave the gang"; "I made new friends" "I moved to a new home or school"; and "I got in trouble with the police".

The qualitative portion of the study relies on interviews from the Multi-Method, MultiSite Study of Gang Desistance. Following the G.R.E.A.T. evaluation, and with additional funding, a subsample of self-reported gang youth were contacted and asked to participate in the study. Gang members were identified for the second study through self-nomination (i.e., answered affirmatively to "are you now in a gang?" question) $(\mathrm{n}=512)$ or the Eurogang

\footnotetext{
${ }^{4}$ Due to this, it is not possible to know whether or not these youth rejoined a gang (i.e., are intermittent gang members).
} 
definition $^{5}(\mathrm{n}=697)$. The research design called for a comparison of stable (i.e., reported membership at two or more consecutive waves) and transient (i.e., reported involvement in at least one, non-consecutive, wave) gang youth. The final sampling frame of 426 was created through a combination of 1) random sampling of transient self-nominated gang youth $(\mathrm{n}=198)$ and those who met the Eurogang definition $(n=97)$ and 2) purposive sampling of stable selfnominated gang youth $(\mathrm{n}=131)$.

The within city sampling frame was shaped by three factors. First, in order to make comparisons across cities the research design called for approximately 30 interviews in four primary cities (Philadelphia, Nashville, Albuquerque, and the DFW suburb). However, the funding agency, National Institute of Justice, requested that all seven cities be included, therefore, three secondary cities were added (Greeley, Chicago, and Portland). Second, the research design called for an exploration of differences across 1) self-nominated and Eurogangdefined gang youth and 2) stable versus transient membership. To accomplish, this researchers planned to interview 30 (15 stable and 15 transient) self-nominated youth in the primary cities and five in the secondary cities. Five additional Eurogang-defined youth would be interviewed in each of the seven cities. While this would have resulted in a sample of 170 youth, quota sampling strategies produced a range from 30 to 36 interviews in the primary sites and 13 to 18 in the secondary sites for a total of $180 .^{6}$

Interviews were completed in the summer of 2012 when the majority of youth had just completed their junior year and were not yet 18 and, therefore, parental consent was obtained for

\footnotetext{
${ }^{5}$ The Eurogang Program of Research defines a street gang as "any durable, street-oriented youth group whose involvement in illegal activity is part of its group identity." For more information on the Eurogang and this definition please see Maxson and Esbensen (2016).

${ }^{6}$ Albuquerque, NM ( $\left.\mathrm{n}=33\right)$; Chicago, IL ( $\left.\mathrm{n}=15\right)$; Dallas/Fort Worth, TX $(\mathrm{n}=36)$; Greeley, CO $(\mathrm{n}=18)$; Nashville, TN $(\mathrm{n}=30)$; Philadelphia, PA $(\mathrm{n}=35)$; and Portland, OR $(\mathrm{n}=13)$
} 
these youth. Following an initial contact letter sent to the parents, youth were visited at their home addresses (obtained during the G.R.E.A.T. evaluation) by interview staff. Upon receiving parental permission, youth participated in an in-depth, face-to-face interview for which they were paid \$20. Interviews took approximately, one hour and, in order to secure privacy, were conducted in a confidential location. The interviews were recorded and later transcribed by project staff resulting in approximately 5,700 pages of transcript. Parent and/or youth refusals were unusual $(5.3 \% ; \mathrm{n}=23)$, but interview staff had difficulty locating youth due to residential mobility $(27.7 \% ; n=118)$ as well as failing to make contact after repeated visits to the address $(20.2 \%, \mathrm{n}=86) .^{7}$

As discussed above, all of the youth selected for participation in this study were identified as gang-involved in at least one of the survey administrations. It is important to note, however, that gang status came up naturally during the interview. Given the retrospective nature of the interviews some of the youth reported gang membership as far back as 2006 during wave one of the G.R.E.A.T. evaluation. Approximately 53 youth did not acknowledge gang involvement during their interviews. ${ }^{8}$ Project staff reviewed and discussed the statuses of the remaining 127 youth. ${ }^{9}$ Of the youth who were identified as involved in a gang, 107 could be classified as desisted from a gang on the basis of affirmative responses to questions regarding

\footnotetext{
${ }^{7}$ Independent sample t-tests using six waves of data from the G.R.E.A.T. evaluation revealed a lot of similarity between youth who completed an interview and those who did not. However, youth who were sampled, but not interviewed were older and held more hitting neutralizations at wave 2 only.

${ }^{8}$ Statistical analyses revealed that these 53 youth reported significantly higher levels of property and violent crime as well as more anger, more neutralizations for hitting, greater adherence to the street code, more commitment to negative peers, and had fewer prosocial peers than nongang youth at the wave of self-reported gang membership. Furthermore, there were no significant differences between these 53 youth and self-nominated gang youth on these variables with the exception of negative peer commitment, which was higher for self-nominated gang youth. ${ }^{9}$ Three to four project members read the transcriptions and formed consensus opinions on the gang status of these youth.
} 
gang desistance. ${ }^{10}$ Similar to the quantitative gang desistance sample, the qualitative gang desisters were comprised of mostly males and Hispanics (see Table 1). The average age of the sample was 17 years, which represented the age at the time of the interview not the age when the respondent left the gang. Due to low numbers and an inability to reach saturation, biracial youth and youth of Native American, Asian, and Kurdish $(n=14)$ decent were excluded from the sample resulting in a sample of 93 gang desisters.

\section{---TABLE ONE ABOUT HERE---}

\section{Analysis Strategy}

The qualitative transcriptions were first broken down in to broad topical areas using NVivo software. The narrative portions that focused on gang desistance were then analyzed via line-byline open and focused coding. By relying upon a modified grounded theory approach, I was able to identify emerging themes associated with motivations for leaving a gang and place them in the context of previous literature (Charmaz 2006; Glaser and Strauss 1967). Throughout the coding process efforts were made to ensure that the themes discussed below represent the most common reasons for leaving a gang in the qualitative sample. Additionally, I examined deviant cases across narratives as well as inconsistencies within the narratives using a constant comparative approach (Glaser and Strauss 1967). Following the initial round of coding, all of the gang desistance narratives were reexamined in order to adjust themes and increase the reliability of results. The reasons given for gang disengagement were examined across and within race/ethnicity and the themes discussed below represent the most common motivations discussed in these data. In addition to quotes taken from the narratives to represent important themes, I make use of percentages when comparing motivations for leaving across race and ethnicity.

\footnotetext{
${ }^{10}$ Disengagement questions included: "Are you still hanging out with this group?"; “What led you to no longer hang out with this group?" and "How did you stop hanging out with them?"
} 
These findings are not able to be generalized to the larger population of gang members, but they are able to provide insight into the presence/absence of differences in motivations along racial and ethnic lines. Moreover, this sample was drawn from seven different cities across the U.S., which is representative of a geographical diversity that is rare in qualitative gang research. When possible, patterns identified within the qualitative data are examined within the quantitative data in order to triangulate differences and check for robustness in the qualitative findings.

Significance was examined through both Pearson's chi-square analysis and Fisher's exact test. Fisher's exact test was deemed appropriate with the qualitative sample because the small sample size led to an expected cell count less than five, which violated the assumptions of Pearson's chisquare.

\section{--TABLE TWO ABOUT HERE--}

\section{Results}

\section{Qualitative Analysis of Push and Pull Motivations}

As shown in Table Two, pull factors were discussed by almost every youth (e.g., a range of $92.2 \%$ to $95.6 \%$ ) in the qualitative sample regardless of race or ethnicity. The most common theme among black (65.2\%), Hispanic (52.9\%), white (52.6) youth all centered on school mobility. School mobility is commonly discussed as either a natural (i.e., middle to high school) or a non-natural transition (i.e., moving to a new school in mid-year). Anthony (black), for example, discussed his non-natural school transition: “It's just because I been goin' to a new school and we was in a different region."

Gang desisted youth also reported that involvement with prosocial friends, activities, and significant others motivated them to say goodbye to gang life. Hispanic (33.3\%) and white (21.1\%) youth more frequently reported meeting new friends as a motivation for gang 
desistance, which was reported less frequently by black youth (17.3\%). While Kelsey (white) simply stated that she “...started hanging out with different people," Andrew (Hispanic) expressed that he had more in common with his new peers, “...I started like meeting some other friends that are, like, just more like me, not using drugs...” Access to prosocial activities, however, does not seem to vary by minority status as the prevalence of this theme was similar across race/ethnicity (e.g., ranging from $21.7 \%$ among black youth to $26.3 \%$ among white youth). Jamal (black) stated: "I stopped hanging around them. Constant football practice, constant projects, constant work..." Alejandro (Hispanic) also discussed work commitments stating: “...I started working, and then, you know, started realizing, you know, started getting more responsibility put on me.” Similarly, Haley (white) discussed how she “...got into cosmetology and that's like all I was focused on doin.'” Pulls associated with prosocial romantic relationships was found to be significantly more common among white youth $(31.6 \%)$ when compared with black (0\%) and Hispanic (13.7\%) youth. For example, Adam (white) highlighted the impact of his girlfriend:

You find a girlfriend...You stop talkin' to your friends because your girlfriend's telling you "Your friends are all hoodlums." And she starts describing all your friends as bad people. And then one day you realize, like, if she keeps talking about all these friends, that I used to be exactly just like, and she's saying so much bad things, like, "Why would I want to be like that?"

Pull motivations can also be associated with experiencing informal mechanisms of social control. During the interviews, black (13.0\%), Hispanic (33.3\%), and white (31.6\%) youth reported that a parent encouraged them to leave the gang, but this theme was less common among black youth. Importantly, not only did parents encourage their child to leave the gang, but many youth indicated that the perceived pain they were causing a parent motivated them to step away from gang life. Jared (white) discussed that "when my mom found out and she was crying 
and I just figured that's not what I want...” Michael (Hispanic) stated that his parents' constant presence motivated him to leave his gang: "I was tired of always seeing my mom always pissed off at me. Trying to ground me 'n stuff so I just thought it ain't worth it. I just kinda like pushed myself away." Similarly, Hector (Hispanic) stated "I stopped. Because they [his parents] told me, like, 'Don't go too far. Don't listen to them jerks. Don't be a, I don’t know, sheep.'” Minority youth, more so than white youth $(5.3 \%)$, reported that an adult other than a parent encouraged their gang desistance. Hispanic youth $(21.6 \%)$ were also more likely to discuss their difficulties in school than black $(13.0 \%)$ or white $(10.5 \%)$ youth. This could come in the form of poor grades, but also school-based punishment. Omar (Hispanic) discussed that "I'd get in trouble a lot so that affect my grades" and Manuel (Hispanic) reported that he had recently been placed in an alternative education center.

Motivations associated with formal institutions were reported significantly more frequently by Hispanic (21.6\%) and white (15.8\%) gang desisters. No black gang desisters reported that official sanctions, through contact with the police or juvenile justice system, played a role in their decision to disengage from gang life. Roberto (Hispanic) discusses how his contact with the juvenile justice system started his gang exit process: "It was at [Juvenile Residential Facility], I started thinking. You know? I find it pointless [to] keep doin' this." This quote from Roberto also helps to illustrate the ability of incarceration to facilitate first doubts about gang involvement and to act as a turning point (Decker et al. 2014a; Roman et al. 2017).

Qualitative push motivations are presented in Table Two as well. The majority of youth reported a push motivation for gang desistance, but significantly fewer black youth (60.9\%), compared with Hispanic (88.2\%) and white (89.5\%) youth, discussed themes that could be classified as push motivations. The most common of these was maturation. It appears that 
feelings of maturation are common across all races and ethnicities with around 40 percent of all youth discussing this theme (e.g., ranging from $43.5 \%$ to $47.4 \%$ ). These narratives typically discussed maturity or feelings of "growing up." Andre (black) discussed, "I became more mature, I'm not beating people up for no reason." While Marco (Hispanic) began thinking of the consequences of his actions, "Like, I started thinking about the consequences before I do something. Unlike I did, before, I didn’t think.” Rebecca (white), stated “...I was a freshman, like stupid I guess and young, I'm still young but I've learned that's not the crowd."

The qualitative interviews also discussed a number of themes that centered on disillusionment with other members of the gang. Importantly these themes were more common among white (52.6\%) and Hispanic (47.1\%) youth. Black gang youth (30.4\%) were less likely to report being disillusioned by the behaviors of their gang peers. Rick (white) discussed how drug use in his gang caused him to distance himself, "I used to hang out with people that claimed gangs. Like, if they continued to do that, doing drugs and all that...I was like 'ehh, I'm not talkin' to you anymore." Eric (Hispanic), discusses the escalation of criminal behaviors in his gang:

I would always see my friends doing stuff, like, they would always be causing trouble, not just sometimes-how we did sometimes. And then I just was like 'Nah, Just leave that stuff.' I didn't really want to hang out with them no more, after that. I don't know, I just, it's just there's a whole different act when you're in a gang.

Additionally, black youth (13.0\%) were less likely to report being tired of intragang "drama" than their white $(31.6 \%)$ and Hispanic $(21.6 \%)$ peers. This could come in the form of violence fatigue, like Mitch (white) explained, "I use to be affiliated with Crip, I'm not anymore...it's just, it's annoying. Too much drama, and too much [pause] pointless violence." Gang desisters also discussed problems with intragang gossip, for example, Jose (Hispanic): 
...that's my friend, we're down like four flats ${ }^{11}$ with each other, but then next week I'm hearin', well that's not what they said about you, they said you're this, they said you're that, so it's like, nah, I ain't got time for none of that.

Finally, only four percent of black youth concluded that their gang peers were not supportive.

This theme was more common among white (15.8\%) and Hispanic (13.7\%) youth. For instance, Charles (Hispanic) discussed how his gang peers refused to join him in a fight, "[I] got jumped with my friends, in front of them, they didn't do nothing...they, didn't step in. So that's when I said, 'Nah. I'm leaving that behind.” Nathan (white) lamented how he felt after going to jail as part of gang activities, "So I went out, ya know, beat up his little cousin up. Got arrested, went to jail. No letters, stamps, nothing."

The role of violence in the lives of gang youth is an important concern for researchers, especially given that gang members account for a disproportionate amount of violence. However, only a small number of youth attributed experiences with direct violence as part of their decision to leave the gang. Both direct and indirect violence were discussed most frequently by Hispanic youth $($ direct $=11.8 \%$; indirect $19.6 \%)$. White youth $(10.5 \%)$, however, discussed experiencing personal victimization more so than black youth (4.3\%). Experiences with vicarious victimization, however, were least common among white youth (5.3\%).

Overall, while pull motivations were ubiquitous in the qualitative sample, black youth were significantly less likely discuss push factors. The impact of school mobility was particularly common among youth regardless of race/ethnicity. However, black youth were significantly less likely to report that a significant other or experience with official sanctions had an impact on their decision to leave the gang. The next section will examine these same processes, when possible, using the quantitative data and compare and contrast findings across the two data sets.

\footnotetext{
${ }^{11}$ Upon inquiry from the interviewer, Jose explained that this is a reference to having four flat tires on a car and represents a close friendship.
} 


\section{Quantitative Analysis of Pull and Push Motivations}

Quantitative reports of push and pull motivations are presented in Table Three. Within the larger quantitative data set the pull motivations were reported most commonly by white gang desisters (61.4\%). While this difference is only marginally significant, it suggests that there are differences in pull motivations present across race and ethnicity. The impact of school or residential mobility in the decision to break away from gang life was not as commonly reported in the quantitative data set (e.g., ranging from $9.1 \%$ to $15.1 \%$ ). In terms of prosocial attachments, the quantitative data are not able to examine prosocial activities or romantic relationships, but these data do indicate that black gang desisters were less likely to report that they made new friends (18.6\%) compared with white (31.8\%) and Hispanic (23.1\%) gang desisters. The quantitative surveys indicate no differences across race/ethnicity for parental encouragement with very few youth reporting that a parent made them leave their gang. White youth $(25 \%)$ were also less likely to report that someone other than their parent encouraged them to leave the gang. Finally, trouble with the police was less likely to be reported by black youth $(8.1 \%)$, followed by white (15.9\%), and Hispanic (23.5) youth.

Changing focus to push motivations, these motivations were significantly different across race/ethnicity with Hispanic youth being significantly more likely to report a push motivation. Feelings of disillusionment with gang life are commonly reported motivations for gang desistance and often encompass vague responses such as "I just left" and "It was not what I thought." These motivations, while not measured in the qualitative data, were equally common across race and ethnicity in the quantitative surveys. Moreover, "I just left" is the most common motivation for gang desistance across both pushes and pulls. Experiencing direct violence 
appears to be more common among Hispanic gang desisters (18.6\%) who were significantly more likely to report that it motivated gang desistance. Fewer black gang desisters, compared with their Hispanic and white peers, reported being personally victimized in both qualitative and quantitative samples. Vicarious violence was also more commonly discussed by gang desisted Hispanic youth with 29.6 percent reporting that a friend was hurt or killed and 16.6 percent reporting that a family member was hurt or killed. Moreover, the quantitative data demonstrates that Hispanic youth were significantly more likely to report that indirect victimization of a friend caused them to step away from the gang.

There are a number of similarities present when comparing across the qualitative and quantitative data sets. First, black youth were least likely to report that making new and prosocial friends motivated them to leave their gang. Second, black youth were also the least likely to discuss experience with official sanctions and trouble with the police. Third, white youth were the least likely to report that they relied on someone other than a parent to help them exit gang life. Fourth, the pattern of push motivations was consistent across both data sets with Hispanic youth, followed by white and black youth being the most likely to report that motivations associated with identity transformations helped them to leave their gang. Finally, the patterning of the role of violence in the gang desistance process is similar across both data sets. This motivation was relatively uncommon in comparison to other pushes as well as pull motivations but it appeared to play a larger role in the gang desistance process of Hispanic youth than white or black youth.

The main inconsistencies between data sets revolved around the prevalence of pull motivations, school mobility, and parental encouragement. While almost all of the youth in the qualitative sample discussed a pull motivation, these motivations were not as commonly reported 
in the quantitative data. Additionally, the reports of school mobility and parental encouragement as motivations were less common in the quantitative data set. These inconsistencies could be due, in part, to retrospective reinterpretation over time. As youth aged and their time in the gang became more distant they may have been more able to identify the turning points that helped them leave the gang. It is also possible that these youth are further along in the gang disengagement process and have moved on from first doubts and anticipatory socialization to turning points and post-exit validation as discussed by Decker and colleagues (2014a). Finally, these inconsistencies may have occurred because of differential measurement across qualitative and quantitative surveys that made these categories less comparable. Parental encouragement, for example, was measured on the quantitative survey as "my parents made me leave the gang." This same conceptualization did not appear as a theme in the qualitative data. Rather, parental encouragement, as stated, often took the form of youth becoming aware of the impact of their status on their parents and family.

\section{Discussion and Conclusion}

Historical attempts to understand the racial and ethnic variation in crime have argued that racial segregation and disadvantage impact access to opportunities, create social isolation and street socialization, and alter experiences within social institutions such as the family and school. While several of these factors have been connected to racial and ethnic variation in offending over the life course (see Elliott 1994, Haynie et al. 2008, Moffitt 1994, and Piquero et al. 2005), they are also helpful in understanding race and ethnic differences in gang exit processes, specifically motivations for leaving the gang. While there were a number of similarities present in the reasons black, Hispanic, and white youth gave for leaving a gang, there were also some important differences. 
Differential reporting of push motivations represent the starkest differences between black gang desisters and their Hispanic and white counterparts. These motivations varied across race/ethnicity in both the quantitative and qualitative data sets with black youth being significantly less likely to report pushes for gang disengagement. This could be evidence of higher levels of street socialization among black youth, which hinders their ability to visualize a nongang identity for themselves (see Ebaugh 1988 and Decker et al. 2014a). Yet, feelings of disillusionment associated with "I just left" and "It's not what I thought" as well as maturation did not vary across race/ethnicity. Therefore, it appears that black youth differ the most on themes associated with disillusionment with gang peer relationships and experiences with violence. While not examined in the quantitative data, the qualitative interviews indicated that black gang desisters were less likely to perceive that their gang peers' behavior was too criminal or that there was too much intragang strife. The absence of these perceptions could be indicative of higher levels of street socialization among black youth and is consistent with prior research that identifies that black youth report more street socialization (Drake and Melde 2014; Freng and Esbensen 2007), have more friends/family that are gang involved (Curry and Spergel 1992), and are more embedded in gang life (Pyrooz et al. 2013).

Additionally, black youth were the least likely to report that violence played a role in their decision to leave their gang. It is not possible, however, to determine if black gang youth experienced no violent victimization or if residing in violent communities and street socialization have resulted in the normalization and acceptance of these behaviors as part of life (Alleyne et al. 2014; Alleyne and Wood 2010). The relative lack of push motivations among black gang desisters is an important area for exploration of future research. Further inquiry is needed to 
determine the how intragang relationships and violence play a role in not only the decision to leave the gang, but also the overall gang desistance processes of black gang youth.

While access to turning points (i.e., pull motivations) was common in the qualitative data, white youth were significantly more likely to report a pull motivation than black youth in the quantitative data. When examining the specific motivations across racial and ethnic categories, one of the largest differences in pull motivations come from experiences with the police. Black youth were significantly less likely to report that their experiences with formal social control agents had an impact on their decision to exit the gang. While this finding may be expected given high levels of justice system contact and poor attitudes toward the police among minority gang youth (Drake and Melde 2014; Freng and Esbensen 2007; Vigil 1988), it is not possible to determine whether or not these youth had any interaction with police or the justice system. In other words, black youth in either sample did not report that experiences with official sanctions motivated them to leave the gang, but I am unable to determine if this was because they had no contact with these agencies or if these interactions were less salient due to the ubiquitous nature of police contact and imprisonment in the black community. Moreover, it is difficult to say, given their status as gang desisters, that these experiences drove youth further into the gang as might be expected based on prior research (see Klein 1995). It may be worthwhile for future research on gang desistance to more closely examine the nuances of experiences with the police and the justice system among black gang desisters. Specifically, researchers should examine how experiences with the police and incarceration result in identity transformations among gang youth.

Additionally, black youth were the least likely to discuss that access to new nongang friends motivated them to leave their gang. This lends support to the argument that racially 
segregated communities are more isolated and produce street socialization as well as Moffitt's (1994) argument that minority youth have greater exposure to life-course persistent peers. Related to this, no black gang desisters discussed the role of a significant other in their gang desistance process, which is largely expected based on literature that suggests that marriage and committed romantic relationships are less common among minority groups (Bulanda and Brown 2007; Elliott 1994; Hawkins et al. 1998; Haynie et al. 2008; South 1993; Wilson 1987).

Hispanic and white youth, compared with black youth, more frequently discussed themes associated with parental encouragement in the qualitative data. In fact, parental encouragement was most common among Hispanic youth, which could be seen as evidence of the larger role of family in Hispanic culture. This social isolation of black youth is demonstrated in the quantitative data as well with motivations associated with adult interventions being less common among black youth. However, black gang desisters were not entirely isolated from prosocial institutions as many of these youth, along with Hispanic and white gang desisters, reported that access to prosocial activities played a role in their decision to leave the gang.

In addition to the differences in social isolation and street socialization among black youth, other differences are worth highlighting due to their consistency with prior research. First, pull motivations associated with school sanctions or getting in trouble at school were more commonly reported by Hispanic youth, followed by black, then white youth. The commonality among Hispanic youth could be a product of the lack of emphasis on education among Hispanic parents (Del Pinal and Singer 1997; Krohn et al. 2011a) or the impact of cultural and language barriers (Bourgois 1996; Krohn et al. 2011a; Padilla 1992; Vigil 1988). However, few white youths reported experiencing sanctions in school, which could be representative of disparity in school discipline practices (Kupchik 2010; Payne and Welch 2010; Skiba et al. 2011; Skiba et al. 
2002). Second, school mobility was common among gang desisted youth regardless of race/ethnicity, but black youth were slightly more likely to report it as a motivation for leaving the gang. This is consistent with prior literature on residential and school mobility, which finds that black youth are more likely to experience changes in neighborhoods/schools (Haynie and South 2005; South and Haynie 2004; South et al. 2007).

The results discussed here do provide some evidence of differences in motivations for leaving the gang among minority youth. However, there are also a number of similarities present when looking within race/ethnicity. When pull motivations are compared within each racial/ethnic category, school mobility, followed by prosocial attachments and activities, were the most common motivations in the qualitative data. Similarly, prosocial attachments played a role in the quantitative data with the most common motivations being identified as making new friends and encouragement from adults. The most common push motivations, within each race/ethnicity, was maturation and being disillusioned with peers' behavior. These motivations were not examined in the quantitative data, which finds that, most commonly, youth of any race/ethnicity report that they "just left" their gang or that a friend was hurt or killed. These similarities as well as the differences discussed are able to help inform policy and programs that seek to reduce gang membership and gang crime.

The findings are also consistent with the age of the gang members. Recall that most of the gang desisters were under the age of 15 at the time of gang leaving, which limited their discussion of certain age-graded turning points such as marriage, military service, or parenthood. ${ }^{12}$ Instead, youth in this sample discussed pull factors are more specific to their age group such as changing schools, making new friends, or experiencing school-level sanctions.

\footnotetext{
${ }^{12}$ While parenthood is common among gang members (Krohn et al. 2011b; Pyrooz et al. 2017; Thornberry et al. 1997), it was not discussed as regularly as other pulls for gang desistance in these data.
} 
That said, while we might expect that maturation to be less commonly discussed in a youth sample, gang desisters in the qualitative sample regularly discussed feelings of maturation. Gang scholars should continue to explore how age impacts the gang desistance process, particularly as it relates to the reasons youth give for leaving gang.

Sampson and Laub (2016) argue that macro-level deterrence-based programs can create turning points that have micro-level impact on criminal behavior and, likely, gang membership. The results presented here indicate that official sanctions and pressure from the police may be specifically beneficial among Hispanic gang members, while black gang desisters reported that experiences with police had no impact on their decision to leave. That said, given the regularity of pull motivations across the sample, gang intervention strategies should be combined with social programs with opportunities provisions that increase social capital. Additionally, as Hispanic gang desisters were the most likely to report direct and vicarious violence as a motivation for leaving the gang they may also be well-suited for trauma-informed interventions that seek to use violent experiences as an opportunity for change (Carson et al. 2013; Decker and Lauritsen 2002; Roman et al. 2017). Finally, the results indicate that programs that increase prosocial bonds to others could facilitate the gang desistance process, regardless of race or ethnicity, by helping to motivate youth to break away from gang life. For example, while black gang desisters were most likely to discuss that mobility played a role in their decision to leave a gang, they did not commonly discuss the role of meeting new friends and significant others as part of their gang desistance process. Results from the white sample indicated that as these youth mature they become disillusioned with the behavior and lack of support of their gang peers and with the conflict within the gang. While all of this might be consistent with a maturation process, access to prosocial individuals may be helpful in speeding up this process, especially given that 
white gang desisters were most likely to report that a significant other impacted their decision to leave.

There are a number of important limitations that should be mentioned. First, the qualitative interviews were retrospective in nature and youth may have incorrectly recalled factors that led to their desistance from gang life. In some cases, youth may have had a recall period of as many as six years in the past. As discussed above, the difference in recall periods between the qualitative and quantitative data sets may have, in part, contributed to the inconsistencies of these results. Regardless, retrospective accounts are believed to be the best way to understand significant life events (such as turning points) because they allow individuals to apply meaning to these experiences (Baxter and Bullis 1986). Second, the nature of the sampling strategy for both the qualitative interviews and quantitative surveys could have led to selection bias. Reliance on school-based samples (e.g., quantitative surveys) and home addresses that were more than one-year old (e.g., qualitative interviews) could have resulted in a sample that was easier to access and, thus, more prosocial in nature. Third, these analyses relied upon a sample of youth gang members, which means that these individuals may have only temporarily desisted from gang life. It not possible to know whether or not these youth re-joined a gang following the survey or interview; therefore, it is a possibility that the motivations reported in this study are explaining only intermittent lapses in gang status.

Finally, while this study was able to contribute to the understanding of racial and ethnic differences in the decision to leave the gang, it was unable to examine variation across gender. Future research should continue to examine the important role that gender plays throughout the gang desistance process. Despite these limitations, the current study was able to make an important contribution to the understanding of racial/ethnic differences in reasons for leaving a 
gang, especially among black youth. Black gang desisters were less likely to report both push and pull motivations and less commonly, compared with their Hispanic and white counterparts, reported that access to prosocial attachments and disillusionment with gang peers contributed to their decision to leave their gang. 


\section{References}

Adler, P., Ovando, C., \& Hocevar, D. (1984). Familiar correlates of gang membership: An exploratory study of Mexican-American youth. Hispanic Journal of Behavioral Sciences, 6, 65-76.

Alleyne, E., Fernandes, I., \& Pritchard, E. (2014). Denying humanness to victims: How gang members justify violent behavior. Group Processes \& Intergroup Relations, 17, 750-762.

Alleyne, E., \& Wood, J. L. (2010). Gang involvement: Psychological and behavioral characteristics of gang members, peripheral youth, and nongang youth. Aggressive Behavior, 36, 423-436.

Anderson, E. (1999). Code of the Streets: Decency, Violence, and the Moral Life of the Inner City. New York: W. W. Norton.

Baxter, L. A., \& Bullis, C. (1986). Turning points in developing romantic relationships. Human Communication Research, 12(4), 469-493.

Bjorgo, T. (2002). Exit Neo-Nazism: Reducing recruitment and promoting disengagement from racist groups. Paper 627:Norwegian Institute of International Affairs.

Bourgois, P. I. (1996). In Search of Respect: Selling Crack in El Barrio. New York: Cambridge University Press.

Bracken, D. C., Deane, L., \& Morrissette, L. (2009). Desistance and social marginalization: The case of Canadian Aboriginal offenders. Theoretical Criminology, 13, 61-78.

Brunson, R. K. (2007). 'Police don't like black people': African-American young men's accumulated police experiences. Criminology, 6, 72-102.

Brunson, R. K., \& Weitzer, R. (2009). Police relations with black and white youths in different urban neighborhoods. Urban Affairs Review, 44, 858-885.

Bulanda, J. R., \& Brown, S. L. (2007). Race-ethnic differenes in marital quality and divorce. Social Science Research, 36, 945-967.

Bursik Jr., R. J., \& Grasmick, H. G. (1993). Neighborhoods and Crime: Dimensions of Effective Community Control. Lanham: Lexington Books.

Bushway, S. D., \& Paternoster, R. (2013). Desistance from crime: A review and ideas for moving forward. In C. Gibson, \& M. D. Krohn (Eds.), Handbook of Life Course Criminology: Emerging Trends and Directions for Future Research (pp. 213-232). New York: Springer.

Carson, D. C., Melde, C., Wiley, S. A., \& Esbensen, F. A. (2017). School transitions as a turning point for gang status. Journal of Crime and Justice, 40, 396-416.

Carson, D. C., Peterson, D., \& Esbensen, F.-A. (2013). Youth gang desistance: An examination of the effect of different operational definitions of desistance on the motivations, methods, and consequences associated with leaving the gang. Criminal Justice Review, $38,510-534$.

Charmaz, K. (2006). Constructing Grounded Theory: A Practical Guide Through Qualitative Analysis. Thousand Oaks: Sage.

Craig, W. M., Vitaro, F., Gagnon, C., \& Tremblay, R. E. (2002). The road to gang membership: Characteristics of male gang and nongang members from ages 10 to 14 . Social Development, 11, 53-68.

Curry, G. D., \& Spergel, I. A. (1992). Gang involvement and delinquency among Hispanic and African-American adolescent males. Journal of Research in Crime and Delinquency, 29, 273-291. 
Decker, S. H., \& Lauritsen, J. L. (2002). Leaving the gang. In C. R. Huff (Ed.), Gangs in America (3rd ed., pp. 51-67). Thousand Oaks, CA: Sage Publications.

Decker, S. H., \& Pyrooz, D. C. (2011). Leaving the gang: Logging off and moving on. Council on Foreign Relations,

Decker, S. H., Pyrooz, D. C., \& Moule Jr., R. K. (2014a). Disengagement from gangs as role transitions. Journal of Research on Adolescence, 24, 268-283.

Decker, S. H., Pyrooz, D. C., Sweeten, G., \& Moule Jr., R. K. (2014b). Validating selfnomination in gang research: Assessing differences in gang embeddedness across non-, current, and former gang members. Journal of Quantitative Criminology, 30, 577-598.

Decker, S. H., \& Van Winkle, B. (1996). Life in the Gang: Family, Friends, and Violence. New York: Cambridge University Press.

Del Pinal, J., \& Singer, A. (1997). Generations of diversity: Latinos in the United States. Population Bulletin, 52, 2-48.

Drake, G., \& Melde, C. (2014). The problem of prediction: The efficacy of multiple marginality in cross-sectional versus prospective models. Journal of Crime and Justice, 37, 61-78.

Ebaugh, H. R. F. (1988). Becoming an Ex: The Processs of Role Exit. Chicago: University of Chicago Press.

Elder, G. H. (1985). Perspectives on the life course. In G. H. Elder (Ed.), Life Course Dynamics: Trajectories and Transitions, 1968-1980 (pp. 23-49). Ithica, NY: Cornell University Press.

Elliott, D. S. (1994). Serious violent offendings: Onset, developmental course and termination. Criminology, 32, 1-22.

Esbensen, F.-A., \& Carson, D. C. (2012). Who are the gangsters? An examination of the age, race/ethnicity, sex, and immigration status of self-reported gang members in a seven-city study of American youth. Journal of Contemporary Criminal Justice, 28, 462-478.

Esbensen, F.-A., \& Huizinga, D. (1993). Gangs, drugs, and delinquency in a survey of urban youth. Criminology, 31, 565-589.

Esbensen, F.-A., Osgood, D. W., Peterson, D., Taylor, T. J., \& Carson, D. C. (2013). Short- and long-term outcome results from a multisite evaluation of the G.R.E.A.T. program. Criminology \& Public Policy, 12, 375-411.

Esbensen, F.-A., Peterson, D., Taylor, T. J., \& Freng, A. (2010). Youth Violence: Sex and Race Differences in Offending, Victimization, and Gang Membership. Philadelphia: Temple University Press.

Esbensen, F.-A., Winfree, J., L. Thomas, He, N., \& Taylor, T. J. (2001). Youth gangs and definitional issues: When is a gang a gang and why does it matter? Crime \& Delinquency, 47, 105-130.

Freng, A., \& Esbensen, F.-A. (2007). Race and gang affiliation: An examination of multiple marginality. Justice Quarterly, 24, 600-628.

Freng, A., \& Taylor, T. J. (2013). Race and ethnicity: What are their roles in gang membership? In T. R. Simon, N. M. Ritter, \& R. R. Mahendra (Eds.), Changing Course: Preventing Gang Membership (pp. 135-149). Washington, DC: National Institute of Justice.

Giordano, P. C., Cernkovich, S. A., \& Rudolph, J. L. (2002). Gender, crime, and desistance: Toward a theory of cognitive transformation. American Journal of Sociology, 107, 9001064. 
Giordano, P. C., Schroeder, R. D., \& Cernkovich, S. A. (2007). Emotions and crime over the life course: A Neo-Median perspective on criminal continuity and change. American Journal of Sociology, 112, 1603-1661.

Glaser, B. G., \& Strauss, A. (1967). The Discovery of Grounded Theory. New York: Aldine.

Gordon, R. A., Lahey, B. B., Kawai, E., Loeber, R., Stouthamer-Loeber, M., \& Farrington, D. P. (2004). Antisocial behavior and youth gang membership: Selection and socialization. Criminology, 42, 55-87.

Hagedorn, J. M. (1988). People and Folks: Gangs, Crime, and the Underclass in a Rustbelt City. Chicago: Lakeview Press.

Hagedorn, J. M. (1994). Homeboys, dope fiends, legits, and new jacks. Criminology, 32, 197219.

Hawkins, D. F., Laub, J. H., \& Lauritsen, J. L. (1998). Race, ethnicity, and serious juvenile offending. In R. Loeber, \& D. P. Farrington (Eds.), Serious and Violent Juvenile Offenders (pp. 30-46). Thousand Oaks: Sage.

Haynie, D. L., \& South, S. J. (2005). Residential mobility and adolescent violence. Social Forces, 84, 361-374.

Haynie, D. L., Weiss, H. E., \& Piquero, A. (2008). Race, the economic maturity gap, and criminal offending in young adulthood. Justice Quarterly, 25, 595-622.

Hill, K. G., Howell, J. C., Hawkins, J. D., \& Battin-Pearson, S. R. (1999). Childhood risk factors for adolescent gang membership: Results from the Seattle Social Development Project. Journal of Research in Crime and Delinquency, 36, 300-322.

Horowitz, R. (1983). Honor and the American Dream. New Brunswick: Rutgers University Press.

Huff, C. R. (1998). Comparing the criminal behavior of youth gangs and at-risk youths. Washington, D.C.: National Institute of Justice: Research in Brief.

Jacques, S., \& Wright, R. (2008). The victimization-termination link. Criminology, 46, 501-530.

Krohn, M. D., Schmidt, N. M., Lizotte, A. J., \& Baldwin, J. M. (2011a). The impact of multiple marginality on gang membership and delinquent behavior for Hispanic, African American, and white male adolescents. Journal of Contemporary Criminal Justice, 27, $18-42$.

Krohn, M. D., Ward, J. T., Thornberry, T., Lizotte, A. J., \& Chu, R. (2011b). The cascading effects of adolescent gang involvement across the life course. Criminology, 49, 991-1028.

Kupchik, A. (2010). Homeroom Security: School Discipline in an Age of Fear. New York: New York University Press.

Laub, J. H., \& Sampson, R. J. (2001). Understanding desistance from crime. Crime and Justice, 28, 1-69.

Logan, J. R., \& Messner, S. F. (1987). Racial residential segregation and suburban violent crime. Social Science Quarterly, 68, 510-527.

Malec, D. (2006). Transforming Latino gang violence in the United States. Peace Review: A Journal of Social Justice, 18, 81-89.

Martinez, J., Ramiro (2002). Latino Homicide: Immigration, Violence, and Community. New York: Routledge.

Maruna, S. (2001). Making Good: How Ex-Convicts Reform and Rebuild Their Lives. Washington, D.C.: American Psychological Association. 
Maruna, S. (2010). Mixed methods research in criminology: Why not go both ways? In A. R. Piquero, \& D. Weisburd (Eds.), Handbook in Quantitative Criminology (pp. 123-140). New York: Springer.

Massey, D. A., \& Denton, N. A. (1993). American Apartheid: Segregation and the Making of the Underclass. Cambridge: Harvard University Press.

Matsuda, K. N., Melde, C., Taylor, T. J., Freng, A., \& Esbensen, F.-A. (2013). Gang membership and adherence to the "Code of the Street". Justice Quarterly, 30, 440-468.

Maxson, C. L., \& Esbensen, F.-A. (Eds.). (2016). Gang Transitions and Transformations in an International Context. New York: Springer.

McNulty, T. L., \& Bellair, P. E. (2003). Explaining racial and ethnic differences in serious adolescent violent behavior. Criminology, 41, 709-748.

Melde, C., \& Esbensen, F.-A. (2011). Gang membership as a turning point in the life course. Criminology, 49, 513-552.

Melde, C., \& Esbensen, F.-A. (2013). Gangs and violence: Disentangling the impact of gang membership on the level and nature of offending. Journal of Quantitative Criminology, 29, 143-166.

Melde, C., \& Esbensen, F.-A. (2014). The relative impact of gang status transitions: Identifying the mechanisms of change in delinquency. Journal of Research in Crime and Delinquency, 51, 349-376.

Miller, H. V., Barnes, J. C., \& Hartley, R. D. (2011). Reconsidering Hispanic gang membership and acculturation in a multivariate context. Crime \& Delinquency, 57, 331-355.

Miller, J. (2001). One of the Guys: Girls, Gangs, and Gender. Oxford: Oxford University Press.

Moffitt, T. E. (1994). Natural histories of delinquency. In E. G. M. Weitekamp, \& H.-J. Kerner (Eds.), Cross-national longitudinal research on human development and criminal behavior (pp. 3-61). Dordrecht: Kluwer Academic Press.

Moloney, M., Hunt, G. P., Joe-Laidler, K., \& MacKenzie, K. (2011). Young mother (in the) hood: Gang girls negotiation of new identifites. Journal of Youth Studies, 14(1), 1-19.

Moore, J. W. (1991). Going Down to the Barrio: Homeboys and Homegirls in Change. Philadelphia: Temple University Press.

Morenoff, J. D., \& Sampson, R. J. (1997). Violent crime and the spatial dynamics of neighborhood transition: Chicago, 1970-1990. Social Forces, 76, 31-64.

National Gang Center (2011). National Gang Survey Analysis, 2011 [online]. Accessed February 22018.

O'Neal, E. N., Decker, S. H., Moule Jr., R. K., \& Pyrooz, D. C. (2016). Girls, gangs, and getting out: Gender differences and similarities in leaving the gang. Youth Violence and Juvenile Justice, 14, 43-46.

Padilla, F. M. (1992). The Gang as an American Enterprise. New Brunswick, NJ: Rutgers University Press.

Payne, A. A., \& Welch, K. (2010). Modeling the effects of racial threat on punitive and restorative school discipline practices. Criminology, 48, 1019-1061.

Peck, J. H. (2015). Minority perceptions of the police: A state-of-the-art review. Policing: An International Journal of Police Strategies and Management, 38, 173-203.

Peterson, D. (2012). Girlfriends, gun-holders, and ghetto-rats? Moving beyond narrow views of girls in gangs. In S. Miller, L. D. Leve, \& P. K. Kering (Eds.), Delinquent Girls: Contexts, Relationships, and Adaptations (pp. 71-84). New York: Springer. 
Peterson, R. D., Krivo, L. J., \& Browning, C. R. (2006). Segregation and race/ethnic inequality in crime: New directions. In F. T. Cullen, J. P. Wright, \& K. R. Blevins (Eds.), Taking Stock: The Status of Criminological Theory (Vol. 15). New Brunswick, NJ: Transaction Publishers.

Piquero, A. R. (2015). Understanding race/ethnicity differences in offending across the life course: Gaps and opportunities. Journal of Developmental and Life Course Criminology, $1,21-32$.

Piquero, A. R., Brame, R., \& Lynam, D. R. (2004). Studying the factors related to career length. Crime \& Delinquency, 50, 412-435.

Piquero, A. R., Moffitt, T. E., \& Lawton, B. (2005). Race and crime: The contribution of individual, familal, and neighborhood-level risk factors to life-course persistent offending. In D. F. Hawkins, \& K. Kempf-Leonard (Eds.), Our Children, Their Children: Confronting Racial and Ethnic Differences in American Juvenile Justice (pp. 202-244). Chicago: The University of Chicago Press.

Pyrooz, D. C. (2014). "From your first cigarette to your last dyin' day": The patterning of gang membership in the life-course. Journal of Quantitative Criminology, 30, 349-372.

Pyrooz, D. C., \& Decker, S. H. (2011). Motives and methods for leaving the gang: Understanding the process of gang desistance. Journal of Criminal Justice, 39, 417-425.

Pyrooz, D. C., McGloin, J. M., \& Decker, S. H. (2017). Parenthood as a turning point in the life course for male and female gang members: A study of within-individual changes in gang membership and criminal behavior. Criminology, 55, 869-899.

Pyrooz, D. C., Sweeten, G., \& Piquero, A. R. (2013). Continuity and change in gang membership and gang embeddedness. Journal of Research in Crime and Delinquency, 50, 239-271.

Roman, C. G., Decker, S. H., \& Pyrooz, D. C. (2017). Leveraging the pushes and pulls of gang disengagement to improve gang intervention: Findings from three multi-site studies and a review of relevant gang problems. Journal of Crime and Justice, 40, 316-336.

Sampson, R. J. (1987). Urban black violence: The effect of male joblessness and family disruption. American Journal of Sociology, 93, 348-382.

Sampson, R. J., \& Groves, W. B. (1989). Community structure and crime: Testing socialdisorganization theory. The American Journal of Sociology, 94, 774-802.

Sampson, R. J., \& Laub, J. H. (1993). Crime in the Making: Pathways and Turning Points Through Life. Cambridge: Harvard University Press.

Sampson, R. J., \& Laub, J. H. (2016). Turning points and the future of life course criminology: Reflections on the 1986 Criminal Careers Report. Journal of Research in Crime and Delinquency, 53, 321-335.

Sampson, R. J., Raudenbush, S. W., \& Earls, F. (1997). Neighborhoods and violent crime: A multilevel study of collective efficacy. Science, 227, 918-924.

Sampson, R. J., \& Wilson, W. J. (1995). Toward a theory of race, crime, and urban inequality. In J. Hagan, \& R. D. Peterson (Eds.), Crime and Ineqaulity. Standford, CA: Standford University Press.

Sanchez-Jankowski, M. (1991). Islands in the Street: Gangs and Urban American Society. Berkeley, CA: University of California Press.

Skiba, R. J., Horner, R. H., Chung, C.-G., Rausch, M. K., May, S. L., \& Tobin, T. (2011). Race is not neutral: A national investigation of African American and Latino disproportionality in school discipline. School Psychology Review, 40, 85-107. 
Skiba, R. J., Michael, R. S., Nardo, A. C., \& Peterson, R. (2002). The color of discipline: Sources of racial and gender disproportionality in school punishment. The Urban Review, 34, 317-342.

South, S. J. (1993). Racial and ethnic differences in the desire to marry. Journal of Marriage and Family, 55, 357-370.

South, S. J., \& Haynie, D. L. (2004). Friendship networks of mobile adolescents. Social Forces, $83,315-350$.

South, S. J., Haynie, D. L., \& Bose, S. (2007). Student mobility and school dropout. Social Science Research, 36, 68-94.

Soyer, M. (2014). The imagination of desistance: A juxtaposition of the construction of incarceration as a turning point and the reality of recidivism. British Journal of Criminology, 54, 91-98.

Taylor, T. J., Turner, K. B., Esbensen, F.-A., \& Winfree, Jr., L. T. (2001). Coppin' an attitude: Attitudinal differences among juveniles toward the police. Journal of Criminal Justice, 29, 295-305.

Thornberry, T. P., Krohn, M. D., Lizotte, A. J., \& Chad-Wiershem, D. (1993). The role of juvenile gangs in facilitating delinquent behavior. Journal of Research in Crime and Delinquency, 30, 55-87.

Thornberry, T. P., Krohn, M. D., Lizotte, A. J., Smith, C. A., \& Tobin, K. (2003). Gangs and Delinquency in Developmental Perspective. New York: Cambridge.

Thornberry, T. P., Smith, C. A., \& Howard, G. J. (1997). Risk factors for teenage fatherhood. Journal of Marriage and Family, 59, 505-522.

Thrasher, F. M. (1927/1963). The Gang: A Study of One Thousand Three Hundred Thirteen Groups in Chicago. Chicago: University of Chicago Press.

Vigil, J. D. (1988). Barrio Gangs: Street Life and Identity in Southern California. Austin: University of Texas Press.

Vigil, J. D. (1999). Streets and schools: How educators can help Chicano marginalized gang youth. Harvard Educational Review, 69, 270-288.

Weitzer, R., \& Tuch, S. A. (1999). Race, class, and perceptions of discrimination by the police. Crime \& Delinquency, 45, 494-507.

Welsh, W. N., Greene, J. R., \& Jenkins, P. H. (1999). School disorder: The influence of individual, institutional, and community factors. Criminology, 37, 73-116.

Wilson, W. J. (1987). The Truly Disadvantaged. Chicago: University of Chicago Press.

Wilson, W. J. (1996). When Work Disappears. New York: Knopf.

Wolfgang, M. E., \& Ferracuti, F. (1969). The Subculture of Violence: Towards an Integrated Theory of Criminology. London: Tavistock Publications. 
Table One: Sample Description Across Race/Ethnicity in both Qualitative and Quantitative Samples.

\begin{tabular}{|c|c|c|c|}
\hline & \multicolumn{3}{|c|}{ Qualitative Gang Desisters } \\
\hline & Black & Hispanic & White \\
\hline \% of Gang Desisted Sample & $22.8(86)$ & $65.5(247)$ & $11.7(44)$ \\
\hline Male & $69.6(16)$ & $58.8(30)$ & $57.9(11)$ \\
\hline Age at Interview (Mean) & $16.96(0.77)$ & $17.31(0.86)$ & $17.11(0.57)$ \\
\hline & \multicolumn{3}{|c|}{ Quantitative Gang Desisters } \\
\hline & Black & Hispanic & White \\
\hline$\%$ of Gang Desisted Sample & $24.7(23)$ & $54.8(51)$ & $20.4(19)$ \\
\hline Male & $68.6(59)$ & $59.1(146)$ & $68.2(30)$ \\
\hline Age (Mean) & $14.17(1.23)$ & $14.51(1.26)$ & $14.09(1.07)$ \\
\hline
\end{tabular}


Table Two: Push and Pull Motivations Across Race/Ethnicity in the Qualitative Sample.

\begin{tabular}{|c|c|c|c|}
\hline & $\begin{array}{c}\text { Black } \\
(\mathrm{n}=23)\end{array}$ & $\begin{array}{l}\text { Hispanic } \\
(\mathrm{n}=51)\end{array}$ & $\begin{array}{c}\text { White } \\
(\mathrm{n}=19)\end{array}$ \\
\hline & $\%(n)$ & $\%(n)$ & $\%(\mathrm{n})$ \\
\hline Any Pull Motivation & $95.7(22)$ & $92.2(47)$ & $94.7(18)$ \\
\hline School Mobility & $65.2(15)$ & $52.9(27)$ & $52.6(10)$ \\
\hline Made New Friends & $17.3(4)$ & $33.3(17)$ & $21.1(4)$ \\
\hline Prosocial Activities & $21.7(5)$ & $23.5(12)$ & $26.3(5)$ \\
\hline Significant Other* & $0.0(0)$ & $13.7(7)$ & $31.6(6)$ \\
\hline Parent Encouragement & $13.0(3)$ & $33.3(17)$ & $31.6(6)$ \\
\hline Encouragement from other Adult & $17.4(4)$ & $17.6(9)$ & $5.3(1)$ \\
\hline School Sanctions & $13.0(3)$ & $21.6(11)$ & $10.5(2)$ \\
\hline Official Sanctions* & $0.0(0)$ & $21.6(11)$ & $15.8(3)$ \\
\hline Any Push Motivation* & $60.9(14)$ & $88.2(45)$ & $89.5(17)$ \\
\hline Maturation & $43.5(10)$ & $43.1(22)$ & $47.4(9)$ \\
\hline Gang-Peer Behavior & $30.4(7)$ & $47.1(24)$ & $52.6(10)$ \\
\hline Intragang Conflict & $13.0(3)$ & $21.6(11)$ & $31.6(6)$ \\
\hline Lack of Gang Support & $4.3(1)$ & $13.7(7)$ & $15.8(3)$ \\
\hline Direct Violence & $4.3(1)$ & $11.8(6)$ & $10.5(2)$ \\
\hline Vicarious Violence & $17.4(4)$ & $19.6(10)$ & $5.3(1)$ \\
\hline
\end{tabular}


Table Three: Push and Pull Motivations Across Race/Ethnicity in the Quantitative Sample.

\begin{tabular}{|l|l|c|c|c|}
\hline & $\begin{array}{c}\text { Black } \\
(\mathrm{n}=86)\end{array}$ & $\begin{array}{c}\text { Hispanic } \\
(\mathrm{n}=247)\end{array}$ & $\begin{array}{c}\text { White } \\
(\mathrm{n}=44)\end{array}$ \\
\hline \multicolumn{2}{|l|}{ Any Pull Motivation^ } & $\%(\mathrm{n})$ & $\%(\mathrm{n})$ & $\%(\mathrm{n})$ \\
\hline & School/Residential Mobility & $39.5(34)$ & $47.8(118)$ & $61.4(27)$ \\
\hline & Made New Friends & $15.1(13)$ & $10.5(26)$ & $9.1(4)$ \\
\hline & Parent Encouragement & $18.6(16)$ & $23.1(57)$ & $31.8(14)$ \\
\hline & Encouragement from other Adult & $7.0(6)$ & $9.3(23)$ & $2.3(1)$ \\
\hline Trouble with the Police* & $17.4(15)$ & $23.1(57)$ & $25.0(11)$ \\
\hline & $8.1(7)$ & $23.5(58)$ & $15.9(7)$ \\
\hline Any Push Motivation* & & & \\
\hline I just left & $47.7(41)$ & $66.4(164)$ & $52.3(23)$ \\
\hline & Not what I thought & $31.4(27)$ & $36.8(91)$ & $34.1(15)$ \\
\hline & I was hurt* & $15.1(13)$ & $17.8(44)$ & $9.1(4)$ \\
\hline Friend was hurt or killed* & $7.0(6)$ & $18.6(46)$ & $11.4(5)$ \\
\hline & Family member hurt or killed & $15.1(13)$ & $29.6(73)$ & $22.7(10)$ \\
\hline & $14.0(86)$ & $16.6(41)$ & $6.8(3)$ \\
\hline
\end{tabular}

${ }^{*} \mathrm{p}<0.05 ; \wedge p=0.06$ 